\title{
Libro-objeto bi-tri dimensional para la enseñanza de los fundamentos del diseño gráfico
}

\author{
Maldonado Yánez Johanna Lorena \\ jlmaldonado2@sudamericano.edu.ec \\ https://orcid.org/0000-0002-1786-5882 \\ Córdova Arcentales Luisa María \\ lmcordova@sudamericano.edu.ec \\ https://orcid.org/0000-0003-2358-6190 \\ Lema Polo John Kleber \\ jlema@sudamericano.edu.ec \\ https://orcid.org/0000-0002-7242-1125 \\ Instituto Superior Tecnológico Particular Sudamericano \\ Cuenca - Ecuador
}

\section{RESUMEN}

Los fundamentos del diseño son conceptos indispensables en los primeros niveles de la disciplina de Diseño Gráfico que ofertan las principales universidades nacionales e internacionales. Conocerlos y dominarlos garantiza parte del éxito tanto en la vida estudiantil como en el ámbito profesional y laboral. En los últimos tiempos la sociedad ha experimentado grandes cambios económicos, sociales, culturales, etc. dados por los avances tecnológicos que signan la era digital. En tal sentido, las universidades en general requieren una actualización en sus procesos de enseñanza y aprendizaje. El presente artículo refleja los resultados de la investigación desarrollada con el objetivo de elaborar un libro-objeto con mecanismos bi-tri dimensionales para la enseñanza de los fundamentos del diseño gráfico. El libro-objeto está dirigido a estudiantes de los primeros ciclos de la carrera y ha sido diseñado teniendo como fundamento la promoción de un aprendizaje verdaderamente significativo y contextualizado. Para el desarrollo del libroobjeto se emplearon métodos y técnicas de la metodología Design Thinking, como resultados de la implementación de las fases de esta metodología: empatizar, definir, idear, prototipar y evaluar; se obtuvo un instrumento didáctico que puede ser utilizado por los docentes de la carrera de Diseño Gráfico del Instituto Sudamericano para la formación de nuevas generaciones.

Palabras clave: libro-objeto; bi tridimensional; fundamentos del diseño; design thinking 


\title{
Book-object bi-tri dimensional for the teaching of the fundamentals of graphic design
}

\begin{abstract}
The fundamentals of design are essential concepts in the first levels of the Graphic Design discipline offered by the main national and international universities. Knowing and mastering them guarantees part of the success both in student life and in the professional and work environment. In recent times, society has experienced great economic, social, cultural changes, etc. given by the technological advances that signify the digital age. In this sense, universities in general require an update in their teaching and learning processes. This article reflects the results of the research carried out with the objective of elaborating a book-object with two-three-dimensional mechanisms for teaching the fundamentals of graphic design. The book-object is aimed at students of the first cycles of the career and has been designed based on the promotion of a truly meaningful and contextualized learning. For the development of the book-object, methods and techniques of the Design Thinking methodology were used, as results of the implementation of the phases of this methodology: empathize, define, devise, prototype and evaluate; A didactic instrument was obtained that can be used by teachers of the Graphic Design career of the South American Institute for the training of new generations.
\end{abstract}

Keywords: book-object; bi three-dimensional; design fundamentals; design

Artículo recibido: 20. Julio. 2021 Aceptado para publicación: 18. Agosto. 2021 Correspondencia: jlmaldonado2@ sudamericano.edu.ec Conflictos de Interés: Ninguna que declarar 


\section{INTRODUCCIÓN}

En los primeros años de los programas de educación superior en Diseño Gráfico existe la asignatura que profundiza el estudio de los Fundamentos de Diseño los cuales son el conjunto de elementos que ayudan a concebir, organizar, proyectar y realizar comunicaciones visuales y gráficas, cuyo objetivo principal es transmitir un mensaje determinado a través de diferentes soportes como folletos, carteles, medios digitales, entre otros. El correcto estudio y comprensión de estos principios es fundamental en la formación de un diseñador, debido a ello existen varios libros sobre el tema que son netamente teóricos, por tal motivo nuestra propuesta se basa en una producción más interactiva.

Dada la importancia del conocimiento de estos principios, se realizó una propuesta editorial que brinde un aprendizaje más moderno en el ámbito del diseño, razón por la cual surge la necesidad de generar un proyecto que integre los conceptos relevantes adquiridos de las seis asignaturas de Cuarto Nivel en el Proyecto Integrador de Saberes, espacio en el que se planteó diseñar y elaborar un libro-objeto para ejemplificar por medio de mecanismos bi y tri dimensionales los Fundamentos del Diseño, con miras a dotar a la institución de recursos didácticos innovadores para la formación de los diseñadores gráficos y romper con el tradicionalismo.

En la encuesta realizada a estudiantes y egresados de la carrera de Diseño Gráfico del Instituto Superior Tecnológico Particular Sudamericano, y dos instituciones de educación universitaria de la ciudad de Cuenca, se evidencia que la asignatura Fundamentos del Diseño es indispensable para la formación del diseñador; no obstante, por tener una mayor carga a nivel teórico, su comprensión tiende a generar complicaciones. De igual manera se visualiza la ausencia de estrategias y recursos didácticos para el desarrollo de los contenidos vinculados con esta asignatura.

\section{MARCO REFERENCIAL}

De acuerdo con (Hinojos, 2018) el Libro-Objeto se define como una estructura espacial por medio de la cual es posible la manipulación, recreación y desarrollo de la actividad sensorial. No solo implica una reconstrucción mental de un relato o la descripción de carácter preciso de algo, sino, que da la posibilidad a que todo lo que se narre sea construido según su contenido. Hace referencia en tal sentido a aquellas obras cuya concepción es casi escultórica por el valor que se les confiere a las características 
tridimensionales, lo cual le ha costado una dudosa reputación dentro del mundo de los Libros-Arte.

Desde el punto de vista de su utilidad el libro-objeto ha sido considerado como un recurso didáctico potencial en el proceso de enseñanza aprendizaje con enfoque significativo. No obstante, la efectividad del mismo, al momento de la aplicación como recurso de aprendizaje, depende de la conexión del contenido, los objetivos de aprendizaje, características de los grupos, necesidades de aprendizaje, métodos y tiempo disponible para el desarrollo de las actividades planificadas. De tal manera que, al considerar estos elementos, el uso del libro-objeto proporcionará beneficios no solo al docente sino también a los estudiantes; promoviendo una mejora de la enseñanza y el desarrollo de clases más interactivas, dinámicas y contextualizadas (Lenis, 2017).

\section{EI Libro-Objeto o Pop Up como recurso didáctico}

Los recursos didácticos se asumen como elementos de apoyo que desde el punto de vista pedagógico permiten reforzar el desarrollo del docente facilitando en gran medida el proceso de enseñanza-aprendizaje; generando mayor interés y motivación por parte de los estudiantes y logrando una articulación más efectiva sobre todo en contenidos teóricos. Entre los principales recursos didácticos empleados en la actualidad destacan el manual o libro de estudio, el cuaderno de ejercicios, y materiales específicos como libros interactivos (Fontecha, 2018).

En el caso de las ilustraciones de mecanismos bi y tri-dimensionales o también conocidas como libro Pop Up, en la actualidad se utilizan en gran medida y se diferencian de los libros o cuentos tradicionales, porque el lector puede manipular de diferentes formas el papel y las figuras que se forman a partir de cortes y dobleces, lo que permite un mayor interés en el lector debido a la experiencia interactiva que ésta proporciona (Narváez, 2016).

Como parte del mecanismo de funcionamiento, las ilustraciones Pop Up, al ser de carácter tridimensional, permiten que se desplieguen figuras de una página para luego volver a su condición plana al momento de pasar de hoja o cerrar el libro-objeto. Cada página del cuento debe ser cuidadosamente elaborada ya que cada corte o doblez permitirá que se desplieguen diferentes imágenes que cautive la atención del niño y le llame la atención durante toda la narración del cuento. Un cuento Pop Up cuenta con tres características primordiales la transformación de imágenes, es decir, una ilustración oculta debe suceder 
a otra, el movimiento por el que personajes, escenarios u objetos ilustrados cobran vida mediante animación; el arte de la tridimensionalidad que da profundidad y efecto de relieve a la escena que se presenta (Calle, 2013).

En cuanto a la producción de libro Pop Up se caracteriza por involucrar a grupos de personas con distintas habilidades que tienen un fin común: desarrollar un concepto a través de distintos saberes. El trabajo colaborativo, entonces, resulta fundamental durante el proceso de creación, pues permite establecer un diálogo o una serie de interacciones entre diferentes visiones de un concepto. En el caso de la creación de un libro Pop Up, existe un texto escrito que pasa a las manos del ingeniero de papel y, según su enfoque, le da movimiento a ciertas escenas o aspectos que considera relevantes; por ello, se puede afirmar que su trabajo es creativo y técnico. (Gavilanes, J. 2012).

De manera sucesiva, el ilustrador incorpora a los mecanismos y a las páginas las ilustraciones en consonancia con el concepto manejado por el grupo, agregando su perspectiva particular del texto e involucrando las técnicas y materiales que considere adecuados. Por tal razón, es importante que los mismos maestros sean los que diseñen este tipo de materiales educativos, claro está, si se quiere enseñar algo nuevo. Las elaboraciones de estos libros móviles constan de una serie de procesos como la impresión, las piezas móviles deben ser recortadas y montadas sobre las páginas del libro-objeto mediante una cadena de producción que precisa el trabajo manual de doblar, insertar pestañas, pegar y enlazar (Gavilanes, J. 2012).

De acuerdo con la geometría las formas tienen dimensiones como largo, ancho y profundidad que nos permiten señalar el volumen de los cuerpos, es decir, conocer sus medidas. En tal sentido, los mecanismos bidimensionales tienen medidas como largo y ancho, es decir, no poseen una estructura que se levanta, sino que ésta es estática, por lo tanto, los mecanismos tridimensionales poseen medidas como largo, ancho $\mathrm{y}$ profundidad, es decir, son estructuras que se levantan y pueden generar un ángulo de 90 grados y darnos la percepción de 3D.

\section{La formación del diseñador gráfico en tiempos de la era digital}

Los desafíos a los cuales se enfrenta el diseñador gráfico son múltiples debido a que la tecnología está en constante cambio y progreso; en esta era digital no es fácil, esto conlleva a estar constantemente actualizado (Khan, 2016). El diseñador gráfico debe mantenerse atento a las nuevas tendencias y preferencias de la industria ya que en la 
medida en que la tecnología evoluciona los softwares, aplicaciones y exigencias del cliente también cambian, por lo cual, las técnicas y recursos del diseñador deben responder a estas transformaciones.

En consecuencia, la formación de diseñadores gráficos debe tener como horizonte la preparación de profesionales comprometidos con las nuevas necesidades y requerimientos de una era marcada por el avance tecnológico. Así mismo, la sociedad exige la preparación de profesionales capaces de tomar decisiones y proponer soluciones adecuadas para problemas de información y comunicación visual.

En el perfil del diseñador gráfico se incluyen varias ramas en las que se desempeña y que en el campo de la experiencia planifica, desarrolla y elabora productos de comunicación o publicidad junto con el marketing, misma que hoy en día es una rama que está en auge por temas de adaptación al desarrollo digital.

El diseño gráfico, visto desde el ámbito profesional como disciplina que desarrolla una actividad creativa y técnica, consiste en crear composiciones que conllevan diferentes aspectos como: informativos, estadísticos, de identidad, de persuasión, tecnológicos, productivos y de innovación, dirigidos a un público objetivo determinado, es por ello, que al mencionar el verbo "diseñar", claramente nos referimos a que es usado para describir al proceso de programar, coordinar, seleccionar y estructurar mensajes de manera que cumpla su función en la sociedad.

Bellucia, (2009) nos manifiesta que, dentro de los procesos del diseño, habilidades y conocimiento, los artes o proyectos varían según la mentalidad y la capacidad interpretativa de los mensajes a comunicar de cada uno de los diseñadores, dando así la habilidad o destreza de obtener sensibilidad, refinamiento visual, memoria gráfica y técnicas que se irán perfeccionando y cambiando a lo largo de nuestra era digital.

Con base a lo expuesto, es pertinente mencionar que el diseño es un proceso de creación visual con un propósito. Por otro lado, el lenguaje visual es aquel que se desarrolla en el cerebro, el cual se encuentra relacionado con la manera en cómo interpretamos lo que percibimos a través de la vista. Para esta visualización se utilizan imágenes, signos o gráficos cuyo objetivo es la transmisión de mensajes, sin embargo, como estudiantes de diseño gráfico, en muchos casos no se pueden aplicar para poder comprender y captar el mensaje de los fundamentos de la teoría del diseño, es por ello que surge la razón de elaborar este innovador método de aprendizaje. 


\section{Diseño y Fundamentos}

El diseño gráfico es una disciplina social y humanística, se sustancia el arte de concebir, planear y realizar las comunicaciones visuales que son necesarias para resolver y enriquecer las situaciones humanas. Directamente anclado en el universo de la vida urbana y del desarrollo tecnológico, el diseño gráfico se ciñe a técnicas, métodos o teorías, las cuales en la actualidad se han abierto por medio de la globalización del mercado (López, 2016), siendo necesario que se lo contemple como el arte de deliberar sobre ellas y sobre la innovación para crear escenarios donde la producción de imágenes incida sobre la vida de la gente, sus conductas de consumo, sus hábitos de lectura y sus necesidades de información.

Por medio de la retórica, el diseño gráfico como tal, puede abrirse a los estudiosos de esta rama ya que emite nuevas perspectivas para el análisis óptimo de diseños y explicación de los mismos, además, de que da paso a la crítica y a la pertinencia de estos por medio del abordaje histórico cultural (Díaz, 2008), pues ésta es el arte de la deliberación para la persuasión, sólo que, proyectada al escenario de la producción y de la imagen, y no sólo de las palabras. Ello significa también que el diseño gráfico es una disciplina teóricopráctica, es decir, que parte de conceptos y de lugares de pensamiento, se ajusta a las condiciones situacionales y su propósito es regular de manera favorable la relación del hombre con su medio ambiente, con la cultura, las creencias y con las instituciones de un modo práctico, eficiente y significativo. (Mendoza, 2014).

Los fundamentos del diseño a través de la idea que expresa Wong W. (1991), son la base de todos los medios visuales: están en el arte, el diseño web e incluso, en pequeños detalles, como las tipografías. Los medios visuales tienen en común que, algunos poseen elementos básicos como la línea, el tamaño, la forma, la textura y el equilibrio. Para comprender más sobre los fundamentos y cuáles son sus características mencionaremos:

\section{- Textura}

Es la cualidad física de una superficie. En diseño, la textura agrega profundidad y tacto a las imágenes planas, los objetos pueden parecer lisos, rugosos, duros o blandos, dependiendo de los elementos. 


\section{- Repetición}

Como su nombre lo indica, esta característica refuerza un elemento o estilo importante en el diseño. Mediante la repetición de módulos o elementos se generan nuevas formas.

\section{- Gradación}

Es una disciplina más estricta. Exige no solo un cambio gradual, sino que se lo realice de manera ordenada, además, genera una ilusión óptica y crea una sensación de progresión, lo que normalmente conduce a una culminación o una serie de culminaciones.

\section{- Radiación}

Centro en posición excéntrica. Una radiación se caracteriza por ser el centro de físico del diseño, pero este punto puede ser colocado en cualquier parte del diseño.

\section{- Anomalía}

Es la presencia de la irregularidad en un diseño en el cual aún prevalece la regularidad. Marca cierto grado de desviación de la conformidad general, lo que resulta en una interrupción, leve o considerable, de la disciplina total.

\section{ESTRATEGIAS METODOLÓGICAS O MATERIALES Y MÉTODOS}

El desarrollo del libro-objeto se realizó en 5 fases contempladas en la metodología de diseño Design Thinking. A continuación, se hace referencia a las actividades ejecutadas en cada una de las fases:

\section{Primera fase. Empatizar}

Con el objetivo de conocer la apreciación de los estudiantes que ya han cursado la asignatura de Teoría del Diseño en la cual se trabaja sobre los fundamentos del diseño, se realizó una encuesta con la cual se identificó que el 95,7\% de los participantes consideran que se puede consolidar, de mejor manera, la captación de los conocimientos por medio de una experiencia física con el objeto de estudio. Por otra parte, también se considera necesario el uso de este recurso ya que la mayoría de estos mismos estudiantes, $58,1 \%$, ha estudiado los fundamentos del diseño por medio de diapositivas y gráficos, el 32,6\% en libros tradicionales a través de lectura y memorización, el 7\% en videos, y el 2,3\% restante mediante animaciones; podemos resaltar que ninguno de estos estudiantes ha tenido la oportunidad de aprenderlos en una plataforma interactiva o libro-objeto.

Se consultó a docentes sobre los métodos, técnicas y características que debería tener un libro-objeto en dicha asignatura y concuerdan que, al ser un contenido netamente teórico, 
pero con conceptos que pueden ser ejemplificados de manera gráfica, existe gran potencial en la posibilidad de materializarlo y generar una experiencia sensorial.

\section{Segunda Fase. Definir}

Para el contenido del presente libro-objeto se optó por usar ecosistemas con la finalidad de generar relación y recordar mediante la experiencia, los ecosistemas son medios con los que nos encontramos familiarizados desde muy niños, de este modo, su relación lograría que el recordar los fundamentos de diseño sea más fácil y su futura utilización sea de manera natural.

En relación al estilo y tendencia del diseño gráfico que decidimos utilizar en el libroobjeto es de carácter sensorial e interactivo, con portada a base de troquel, estructura y encuadernación artesanal, la cromática aplicada es con colores primarios que hace contraste con la base de colores tierra, los materiales con los que se decidió trabajar, en un $60 \%$, son cartulinas ecológicas creadas a base de materiales reciclables, goma no tóxica y sin ácido, todo esto con la finalidad de cuidar el medio ambiente y que la manipulación del producto sea seguro y su durabilidad extendida. En una primera instancia se prevé dotar de este libro-objeto a la Biblioteca "Daniel Claudio Perazzo Logioia" del Instituto Superior Tecnológico Particular Sudamericano, y en lo posterior a instituciones de educación superior que requieran incorporarlo según su malla académica en relación a la temática de fundamentos del diseño; el tiempo estimado de ejecución del libro-objeto se desarrolló en un mes, dividido en dos fases, la primera fase de investigación y la segunda de construcción, pruebas de material, impresiones, encuadernación y acabados del producto final.

\section{Tercera Fase. Idear}

En esta fase se revisaron los fundamentos del diseño del libro de Wucius Wong, y se optó por escoger 5 de los 12 conceptos estudiados sobre diseño bi-dimensional que se encuentran en la publicación. La razón de escoger esa cantidad de temas es porque, Silvia H. Coullaut, de Libracos, recomienda y manifiesta que un libro-objeto debe elaborarse con un número impar ya que el objetivo es que tenga un centro que se pueda trabajar a 180 grados de apertura, a estos 5 criterios se decidió representarlos en diferentes ecosistemas. Al ser libro-objeto un medio interactivo se definió que el texto utilizado sea mínimo y relevante, y que se encuentre en un espacio reducido en cada página con el objetivo de resaltar los gráficos y mecanismos, es necesario que el contenido textual esté 
presente ya que corresponde al concepto teórico que tiene relación con el criterio de diseño.

\section{Los fundamentos seleccionados, por su relevancia conceptual, fueron:}

- Repetición, ecosistema de ciudad para representar a Cuenca ya que encontramos edificaciones estructuradas mediante la repetición de formas, este fundamento se aplicó a través de la técnica de corte y doblez, o kirigami, que consiste en el arte de cortar papel obteniendo así una hoja de papel plana con partes fundidas. (Duarte, 2020)

- Gradación, se representó por medio del ecosistema montañoso que se forma con un punto de fuga, el mecanismo escogido fue bidimensional con el objetivo de resaltar la gradación al momento de conseguir el efecto.

- Radiación, escogimos un mecanismo tridimensional en un ecosistema de selva donde el punto principal de radiación se centra en la cola de un pavo real.

- Textura, trabajamos con el ecosistema planetario para representar en los planetas del sistema solar, diferentes tipos de texturas.

- Anomalía, representamos con el ecosistema marino, debido a que generalmente la forma de las olas es similar, pero podemos identificar cierto grado de desigualdad provocado por otros factores naturales.

\section{Cuarta Fase. Prototipo}

El proceso llevado acabo para la realización del prototipo se describe a continuación:

\section{Bocetaje de mecanismos}

Para iniciar el proyecto se realizaron distintos bocetajes de los mecanismos que se utilizan en el estilo Pop Up con la finalidad de escoger los más idóneos para las representaciones de los distintos ecosistemas y fundamentos elegidos.

En primera instancia se realiza bocetajes en cartulinas simples sin diseño los mecanismos iniciales escogidos fueron de corte y doblez, que se logra realizando cortes en la cartulina a distancias iguales en ambos lados y también dobleces hacia adelante y hacia atrás para dar la apariencia de cubos, se realizaron tambien estructuras en papel 2D generando un punto de fuga, se utilizaron diferentes texturas para la elaboración del ecosistema de la vía láctea con sobre posición de papel, se generó una estructura concéntrica que se forma al abrirse, y utilizamos el método de troquel y papel pegado unos sobre otro para generar 
relieves. El proceso llevado a cabo para la realización del prototipo se describe a continuación.

\section{Diseño digital del libro-objeto}

Para este proceso se utilizó la herramienta digital de diseño gráfico, Adobe Illustrator, que nos permitió crear vectores con medidas exactas y considerar una amplia gama cromática. Los tonos fríos y cálidos primarios se escogieron para aplicar en los ecosistemas, que hacen contraste con el color tierra de la estructura del libro-objeto. En la imagen 1 se observa la pantalla del software utilizado con los diseños tanto de la portada del libro-objeto como de las diferentes páginas con su respectivo contenido.

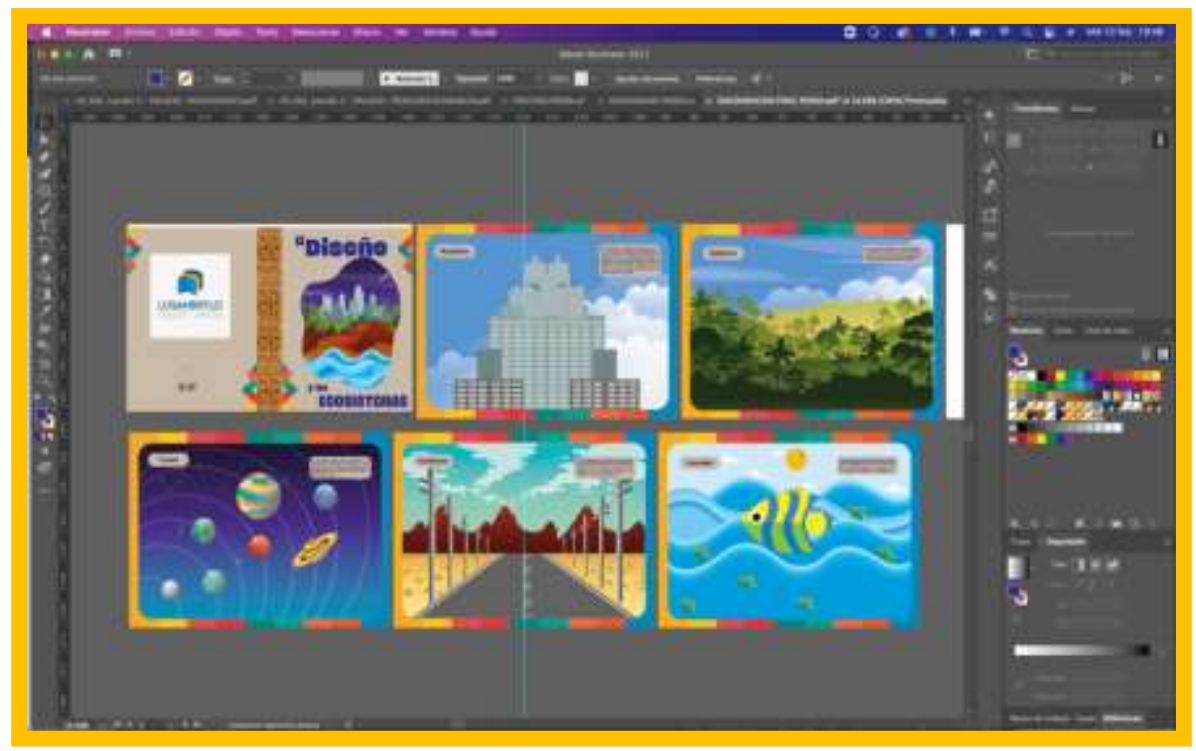

\section{Imagen. 1 Vectorización de fondos.}

\section{Impresión}

Realizamos la impresión con la finalidad de hacer pruebas de color, verificar la calidad de las ilustraciones sobre materiales, tamaños adecuados y para corroborar que la tipografía mantenga los criterios de legibilidad y leibilidad en el producto final. En la imagen 2 se visualiza la portada del libro-objeto que posteriormente será troquelada para su posterior ensamblaje. 


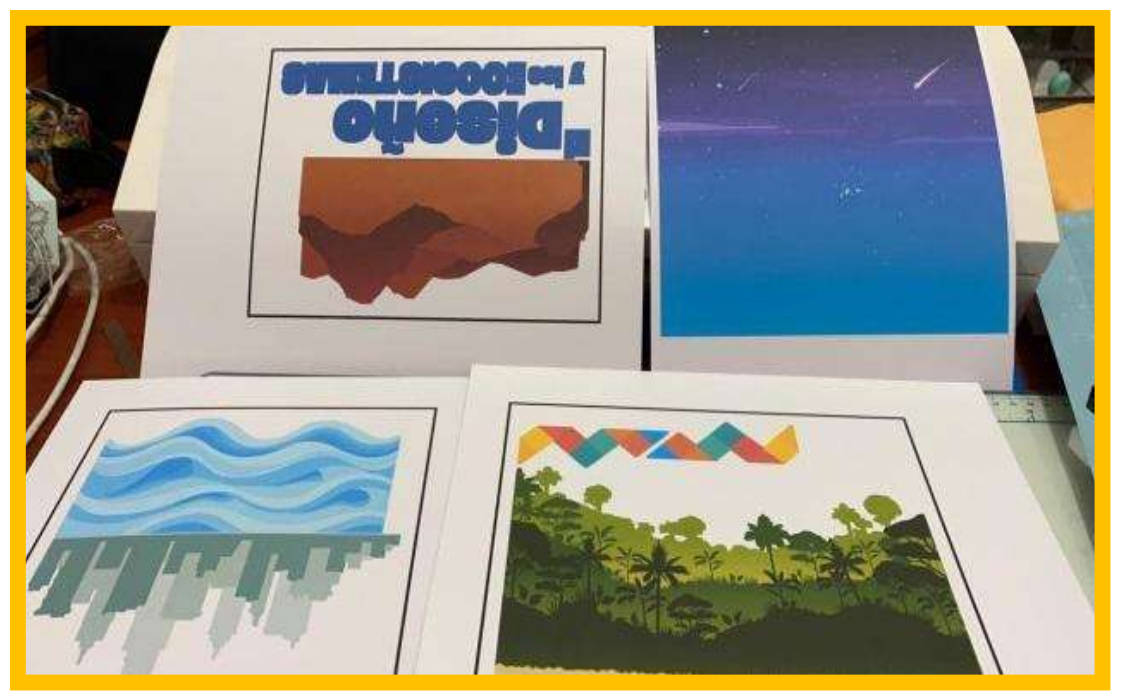

Imagen. 2 Impresión de portada.

\section{Maquetación de libro-objeto}

Una vez que se imprimieron los fondos de las páginas del libro-objeto, se realizaron las pruebas correspondientes de mecanismos y de sus partes generando un prototipo que nos sirvió para corregir ajustes de tamaño, impresión y ensamblaje, todo esto con el objetivo de proceder con el armado definitivo y que el producto final sea de gran calidad. En la imagen 3 se observa el prototipo de un mecanismo bidimensional sobre un sistema montañoso con el fundamento de gradación, en las imágenes 4 y 5, de igual manera, se realiza la prueba de los mecanismos en cada ecosistema y se pudo evidenciar que el texto perdía legibilidad sobre la imagen, criterio que se corrigió con el cambio de ubicación del texto y aplicando sobre un fondo para que tenga una correcta continuidad de la lectura.

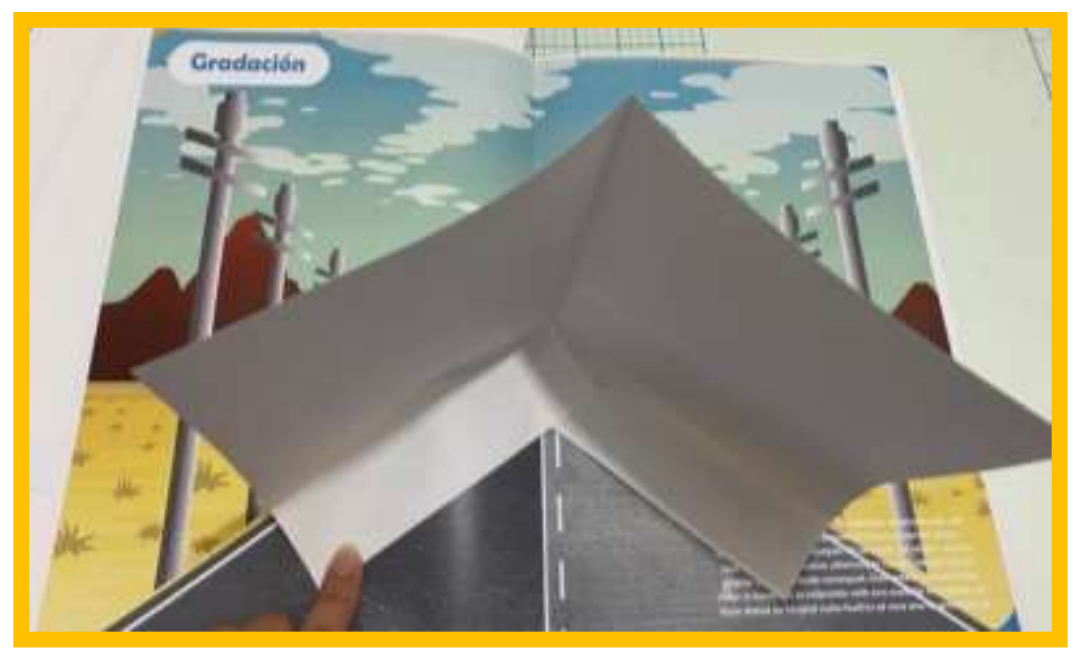

Imagen. 3 Prototipado de mecanismo 2D. 


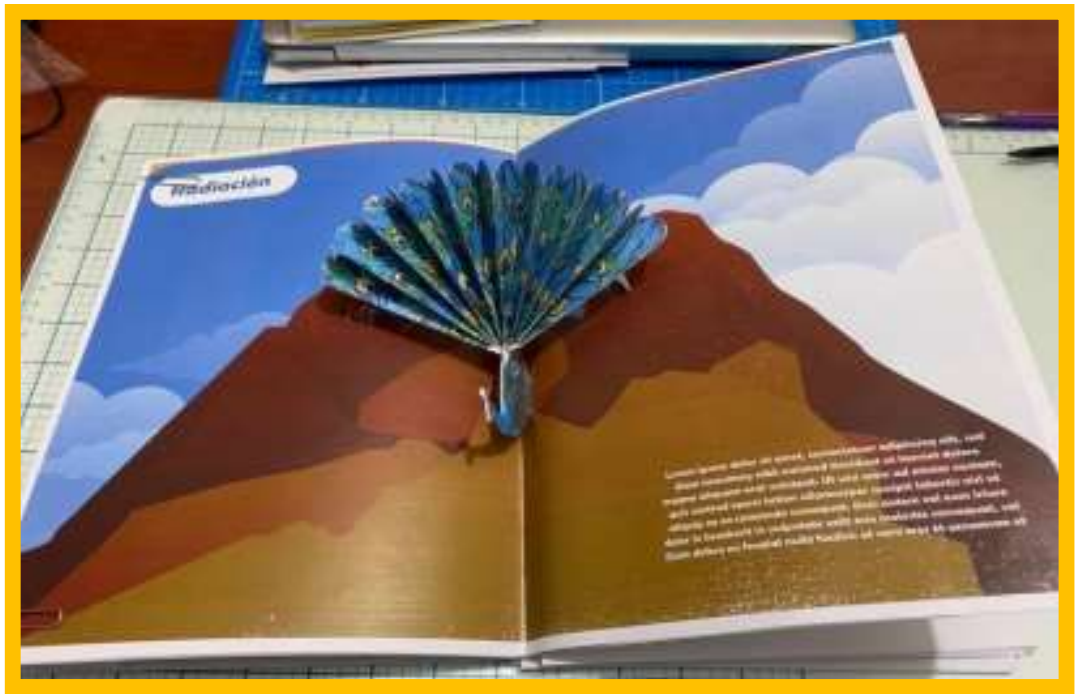

Imagen. 4 Prototipado de pavo real.

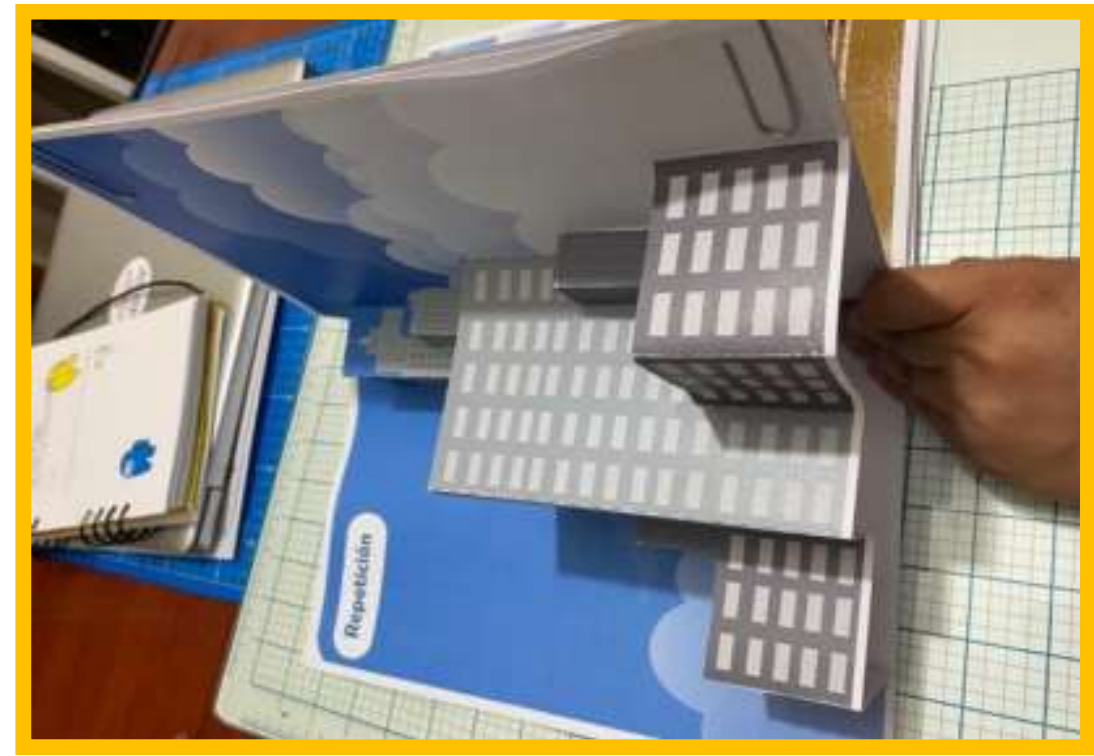

Imagen. 5 Prototipado de edificio, mecanismo corte y doblez.

\section{Troquelado}

Una vez que todas las piezas tuvieron los ajustes necesarios tanto en tamaño y color, se procedió con el troquelado o corte en plotter definitivo de los distintos mecanismos y componentes del libro-objeto. En la imagen 6 podemos observar cómo quedan cortadas las diferentes partes de la página del libro-objeto para su posterior armado. 


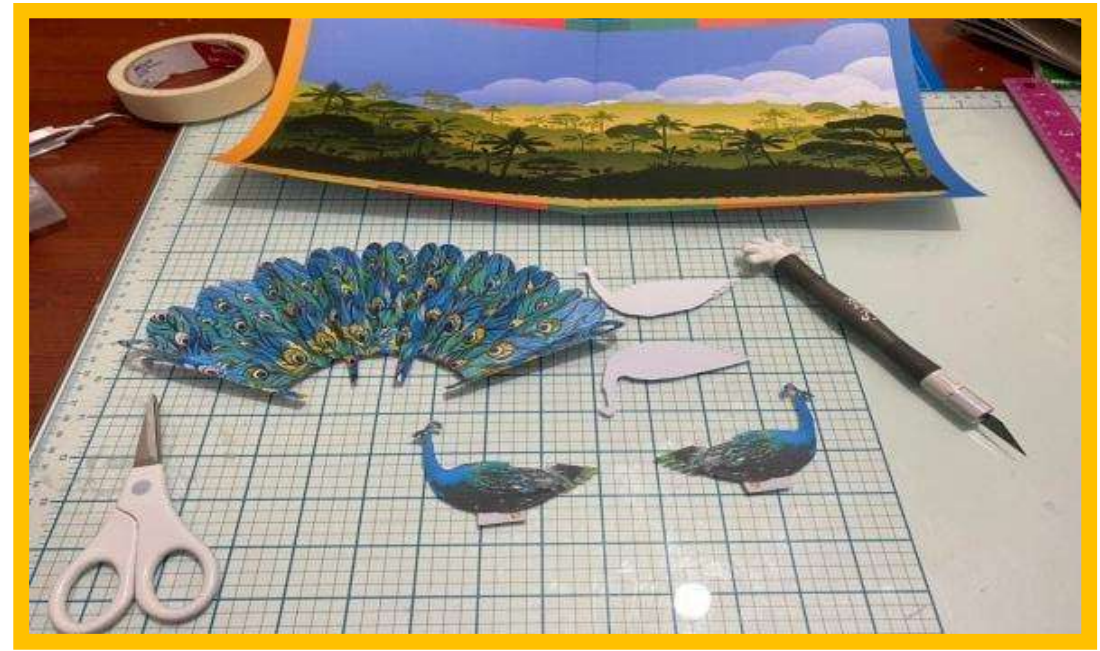

Imagen. 6 Troquelado de pavo real.

\section{Ensamblaje}

Una vez que todos los mecanismos fueron armados en sus páginas, procedimos a pegar cada hoja en lo que sería la base del libro-objeto para dar un fondo uniforme y resistente al mismo, en este caso, optamos por utilizar un material ecológico como base de la estructura y para su encuadernación.

Aquí decidimos aplicar en la primera, quinta y novena página o primer, tercer y quinto fundamento, los mecanismos que necesitan más espacio para que su apertura tenga una amplitud de $180^{\circ}$. En la imagen 7 se observa cómo queda el mecanismo bidimensional al momento de realizarse la apertura del libro-objeto, en este mecanismo obtenemos un punto de fuga y la relación de tamaño y espacio. En la imagen 8 se aprecia la utilización, ya de manera gráfica, que se adapta de manera perfecta al ecosistema que se representa.

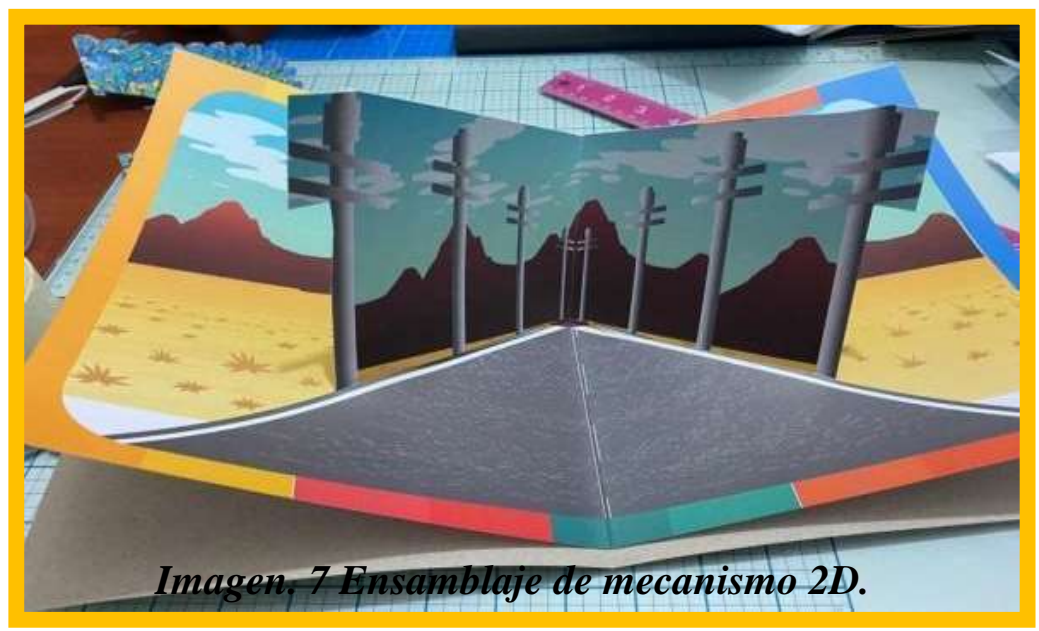




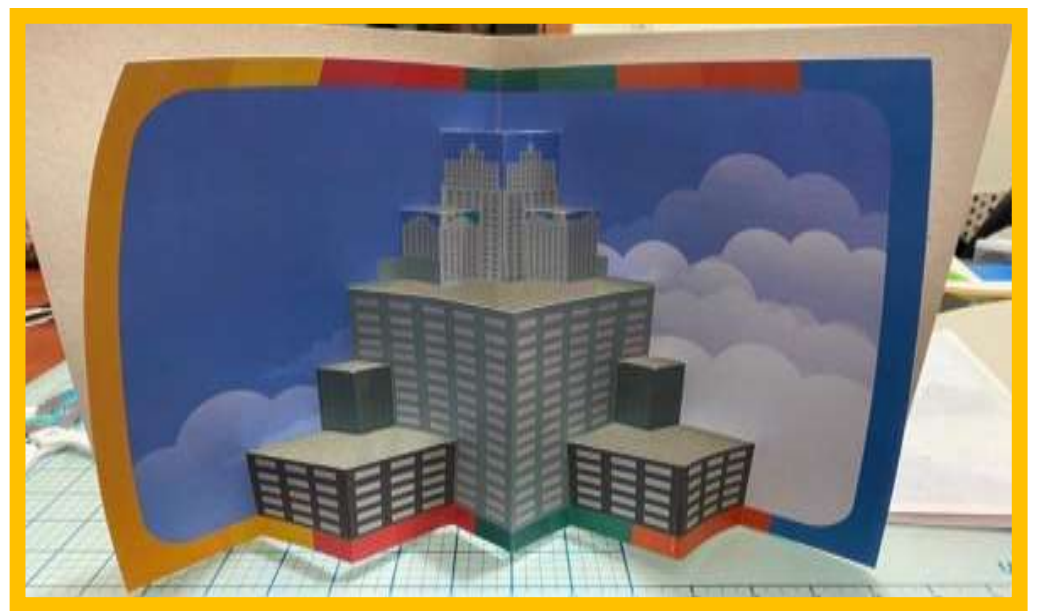

Imagen. 8 Ensamblaje de mecanismo de corte y doblez.

\section{Encuadernación}

La encuadernación es sencilla, el lomo en material de corcho, que contrarresta a la llamativa cromática del libro, el cajo utilizado es de $0,75 \mathrm{~cm}$. para que la apertura del libro-objeto sea adecuada y se pega antes de llegar al lomo, para que, al momento de su manipulación tenga el suficiente aire al abrirse y cerrarse.

La portada del libro-objeto como se observa en la imagen 9 está realizada en troquel, que genera una apariencia de profundidad y contiene partes que, posteriormente, se encontrarán en las páginas internas y distintos ecosistemas.

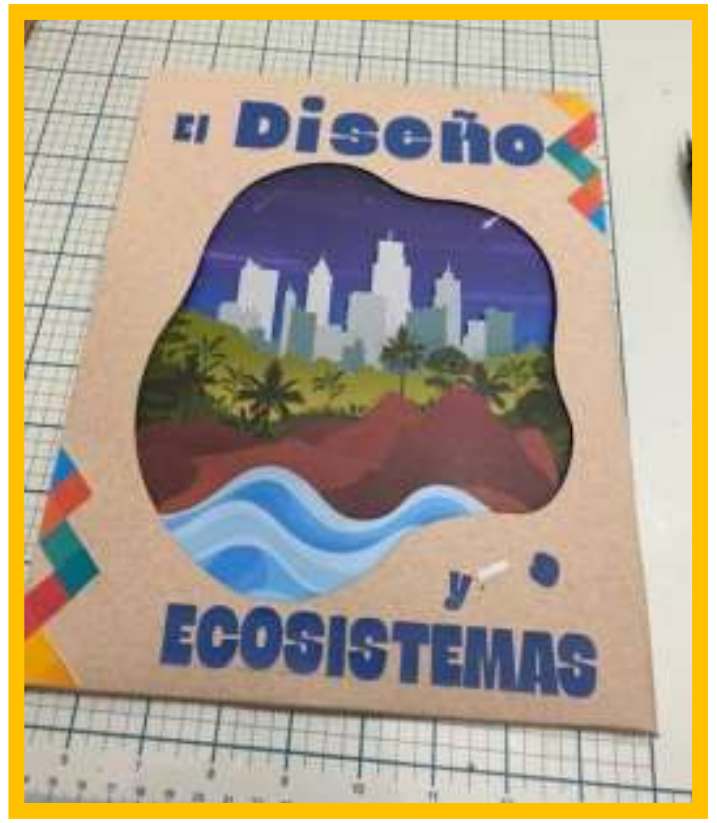

Imagen. 9 Portada del libro-objeto. Técnica troquel. 


\section{Producto Final}

En la imagen 10 se puede apreciar la portada tanto posterior como frontal del libro-objeto ya armado, con lomo de corcho, sobre cartulina ecológica reciclada y con sistema de troquel.

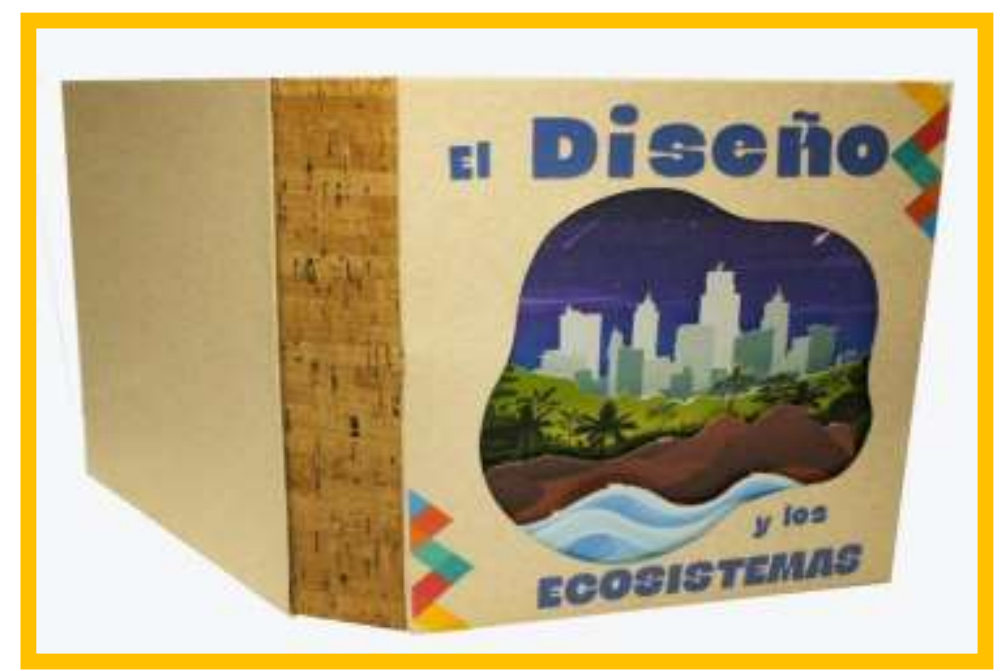

Imagen. 10 Libro Objeto. Portada frontal y posterior.

\section{Quinta Fase. Testear}

El libro-objeto, como producto final, se presentó a los docentes de Cuarto Nivel de la carrera de Diseño Gráfico del Instituto Superior Tecnológico Particular Sudamericano, el cual contaba con los parámetros solicitados por los mismos e incorporaba los temas tratados en las asignaturas cursadas. La funcionalidad del libro-objeto hizo que aprobáramos el nivel antes mencionado.

Debido a la situación actual de salubridad por la que atraviesa todo el mundo, el uso del libro-objeto, por parte de los estudiantes, se verá postergado hasta que se pueda regresar a la modalidad presencial, esperamos que genere una excelente experiencia de aprendizaje, así como lo supieron manifestar en la encuesta realizada.

\section{CONCLUSIÓN O CONSIDERACIONES FINALES}

La formación de diseñadores gráficos del siglo XXI requiere nuevas técnicas de aprendizaje. Mediante los datos obtenidos en la encuesta aplicada a estudiantes de diferentes ciclos de la carrera Diseño Gráfico se pudo evidenciar que los fundamentos del diseño son conceptos de gran importancia en la formación académica, no obstante, existen pocos recursos o solamente recursos teóricos al momento de ser impartida.

El libro-objeto fue desarrollado como recurso didáctico de apoyo para la enseñanza de la asignatura de Teoría del Diseño en el Instituto Superior Tecnológico Particular 
Sudamericano, así también, una referencia y ejemplificación de la técnica utilizada para la elaboración de dicho libro-objeto.

Como principal método de investigación, el mejorar el aprendizaje de los estudiantes de la carrera de Diseño Gráfico sobre los fundamentos del diseño, el uso de este libro-objeto, facilita en un $70 \%$ la compresión de los temas teóricos, dejando un 30\% que cubrir de manera práctica, haciendo que el aprendizaje sea $100 \%$ creativo y experimental, uniendo las emociones y aspectos cognitivos del estudiante.

Mediante el uso de mecanismos de diseño y adaptando a los métodos de enseñanza y encuadernación se puede elaborar un libro-objeto que enmarque los conocimientos que se pretende impartir a los estudiantes como base fundamental del diseño. Podemos también dirigirnos al estudiantado de manera más interactiva, precisa y directa, ya que, al asociar los mecanismos con los diferentes conceptos de diseño, se puede transmitir la información de manera práctica generando un vínculo de experiencia en el estudiante, considerando que al usar el hemisferio derecho que se encarga de la creatividad e ideas y en conjunto con el izquierdo que retiene información, aumentamos la probabilidad de asimilación de los conceptos.

\section{LISTA DE REFERENCIAS}

Antoni Ballester. (2005). El aprendizaje significativo en la práctica. Equipos de investigación y ejemplos de didáctica en la geografía. V Congreso Internacional Virtual de Educación, 1-9.

Raul Bellucia. (06 de junio de 2009). Proceso vs Resultados de enseñanza del diseño. Obtenido de Faroalfa: http://foroalfa.org/articulos/procesos-vs-resultados-enlaensenanza-del-disenoLuis Antonio Díaz, R. (2008). La retórica en el diseño gráfico. Investigación y Ciencia, vol. 16(npum. 41), 33-37. Obtenido de https://www.redalyc.org/pdf/674/67404106.pdf

Jakeline Duarte. (2020). Ambientes de Aprendizaje. Una aproximación conceptual. Estudios Pedagógicos, 29, 97-113. doi: http://dx.doi.org/10.4067/s071807052003000100007

ANA MAZOY FERNÁNDEZ. (1998). El Libro Objeto, como recurso didáctico. Obtenido de https://bit.ly/2ViQo9X

Yorely Fontecha Parra. \& Jesús Morantes Ramírez. (2018). Libro pop-up: Un recurso educativo como estrategia en la construcción de conocimiento biológico desde la 
perspectiva de didáctica de las ciencias. Obtenido de UNIVERSIDAD PEDAGÓGICA NACIONAL FACULTAD DE CIENCIA Y TECNOLOGÍA DEPARTAMENTO DE BIOLOGÍA BOGOTÁ: https://bit.ly/37dolvlv

Monica de la Cruz Hinojos. (16 de agosto de 2018). En las márgenes del libro: Construir espacios para sentir. REVISTA DE LA FACULTAD DE ARTES Y DISEÑO PLANTEL TAXCO. Obtenido de http://revista925taxco.fad.unam.mx/index.php/2018/08/16/en-las-margenes-dellibro-construir-espacios-para-sentir/

Farhan Khan. (2016) hardest \& most challenging part of being a graphic designer, Pakistán.

Recuperado de: https://bit.ly/2VbBId2

Luis Daniel Mancipe López. (noviembre de 2016). EL DISEÑO GRÁFICO Y DE COMUNICACIÓN. UNA APRÓXIMACIÓN AL OBJETO DE ESTUDIO Y A LA PERTINENCIA DE LA PROFESIÓN EN LAS PYMES MANUFACTURERAS COLOMBIANAS. UNIVALLE. Obtenido de https://bit.ly/2TSWoWI

Yorelly Fontecha Parra \& Jesús Morantes Ramírez, (2018). Mattos L. (1963). Compendio de Didáctica General. Buenos Aires: Kapelusz.

Alejandro Tapia Mendoza. (2014). Hacia una definición del diseño gráfico. Universidad Autónoma de Ciudad Juárez, Instituto de Arquitectura, Diseño y Arte: Departamento de Diseño. Obtenido de http://www3.uacj.mx/IADA/DD/LDG/Documents/LECTURAS\%202014/Lectur a\%20de1\%20Mes\%20-\%20Enero2014\%20$\% 20$ Definicion\%20de\%20Diseno.pdf

Julia Sagar, (2017) 14 biggest challenges in design. Londres. Recuperado de: https://www.creativebloq.com/graphic-design/14-biggest-challenges-designtoday-31619475

Wucius Wong. (1991). Fundamentos del diseño bi y tri-dimensional. Barcelona: Editorial Gustavo Gili, S. A. Obtenido de https://bit.ly/2Vrg2Jv

Ellen Lupton; Jennifer Cole Phillips. (2009) Diseño Gráfico: Nuevos fundamentos. Barcelona (España). Ediciones gustavo Gili, SL. 
Rosa Tabernero Sala. (2019) El objeto libro en el universo infantil : la materialidad en la construcción del discurso[Zaragoza : Prensas de la Universidad de Zaragoza.] Permalink: http://digital.casalini.it/9788417873042

Ana Mazoy. (1998). El Libro Objeto, como recurso didáctico. Tendencias pedagógicas, (1), 193-199.

Éric Vigne. \& TORREGROSA, G. (2017). El formato libro y el libro objeto. Trama \& Texturas, (32), 15-20.

Ana Angelica Ulloa, L. (2018). Fundamentos del diseño. Desde la perspectiva de la complejidad. Editorial Digital del Tecnológico de Monterrey.

Jana Gonzalez Meneses. (2018). El Design Thinking y el desarrollo de la creatividad en la educación. Un estudio aplicado a los estudiantes de la carrera de Diseño Gráfico en la Universidad de Ciencias Aplicadas, cuarto ciclo 2017-2018.

Mora Gontovnikas. (2017). Arte Pop y Diseño Gráfico. 